\title{
The Level of Academic and Environmental Stress among College Students: A Case in the College of Education
}

\author{
Dawit Yikealo, Bereket Yemane, Ikali Karvinen \\ Eritrea Institute of Technology, College of Education, Mainefhi, Eritrea \\ Email: dawityikealo@gmail.com
}

How to cite this paper: Yikealo, D., Yemane, B. and Karvinen, I. (2018) The Level of Academic and Environmental Stress among College Students: A Case in the College of Education. Open Journal of Social Sciences, 6, 40-57.

https://doi.org/10.4236/jss.2018.611004

Received: October 7, 2018

Accepted: November 5, 2018

Published: November 8, 2018

Copyright (c) 2018 by authors and Scientific Research Publishing Inc. This work is licensed under the Creative Commons Attribution International License (CC BY 4.0).

http://creativecommons.org/licenses/by/4.0/

\begin{abstract}
Stress that can arise from various academic and environmental aspects is very common among college students. Uncontrollable stress lowers academic, social, environmental, psychological and physical adjustment. In this research, the level of academic and environmental stress among College of Education (CoE) in EIT was intensively discovered. It was explored in relation to the students' cumulative GPA and gender. The major academic and environmental factors that contribute to more stress among the college students was of a great interest in the study. Moreover, investigating the stress management strategies practiced by the college students was among the main concerns. To obtain a reliable data, a total of 107 students of $2^{\text {nd }}, 3^{\text {rd }}$, and $4^{\text {th }}$ year of the College of Education were randomly and conveniently selected to fill the self-developed questionnaire and in the focus group discussion. The data were analysed with the help of descriptive and inferential statistical techniques. The data computation process was assisted by a Software Package for Social Sciences (SPSS). The study findings reveal that majority of the College of Education students experience a moderate level of academic and environmental stress. Gender and Cumulative GPA of the students were also found not to have statistically significant difference. However, CGPA was merely found to have a slight statistically significant relationship with the level of environmental stress. Majority of the students expressed as they practice various positive stress management strategies. The study is expected to contribute a lot in assessing the level of stress and identifying the most stressful academic and environmental factors.
\end{abstract}

\section{Keywords}

Stress, Stressors, Academic Stress, Environmental Stress 


\section{Introduction}

Stress is a common element in the lives of every individual, regardless of race or cultural background [1]. Stress is the insistent outcome caused by various stable and strain routine tasks of every part of our life. The changeover from adolescence to adulthood is a complicated journey in academic life of college students. In this stage, college students face fast physical, social and mental changes along with they may experience unsuitability and adaptableness. College students constantly have more multifaceted inconvenience due to academic pressure, adaption to new environment, fear of failure, struggle to create uniqueness, inferiority, attaining social familiarity, etc. [2].

College life is one of the most sparkling and unforgettable experiences in an adolescent's life. In colleges, adolescents enjoy a vivacious environment, a company of friends and various academic and co-curricular activities which enrich and nurture their academic life and hereafter prepare the adolescent for adulthood [2].

College students are vulnerable to various stress inflicting situations which in turn tends them to be continually creative in managing stress feelings. The stress producing factors among college students can arise from the subject or from the environment. These stressors are related to academic, socio-economic and personal successes in which the subject's failure to overcome leads to stress [2]. College students often meet their future partners in college. Along with it, they also require preparation and focus to perform well in academic works of various subjects and disciplines. However, college students very often experience inconsistent outcomes. Therefore, ineffective coping can lead to anxiety, drinking problems, depression and a multitude of other mental health problems amongst college students. Moreover, elevated stress levels amongst college students can result in a decline in the academic accomplishments, and affect both the physical, social and mental health of students. The issue of stress among college and university students has been a focus of many researchers for several years [3].

Correspondingly, the present paper aims to address the level of academic and environmental stress among the College of Education (CoE) students. Besides, the level of each stressor will be examined in relation to various demographic variables. Furthermore, this research will explore the current stress coping strategies practiced by the college students to assist the activity of the Guidance and Counselling Center (GCC) in the college. The activity and outcomes of the GCC in the college is highly dependent on the results of such relevant studies.

\section{Aim of the research}

This research is intended to explore the levels of academic and environmental stress experienced by College of Education students.

\section{The Rationale of the study}

The researchers are eager to know the how stressful is the academic and environmental aspects for students in the CoE. Besides, to determine what particular academic and environmental stressors are the most stress provoking among 
students in the college. Finally, the researchers believe that the research results will contribute a lot in suggesting stress coping strategies for all stakeholders.

\section{Research Objectives and Questions}

This research was conducted to meet the following specific objectives,

1) To explore the level of academic and environmental stress among students in College of Education.

2) To find out whether demographic variables like gender, CGPA, student permanent address and year of study speak about the level of academic and environmental stress.

3) To identify the major academic and environmental components that causes of students' stress in the College of Education.

4) To investigate the stress management strategies practiced by the college students.

This research was also intended to answered the following questions,

Main Research Question: What is the level of academic and environmental stress among College of Education?

Sub-research Questions. 1) What are the major academic and environmental components that cause stress in the college students? 2) Is there any relationship between level of stress and students' gender, CGPA, student permanent address and year of study? 3) What are the existing stress management skills of the college students?

\section{Conceptual Framework of the study}

As it is indicated in the Figure 1, the conceptual framework of the study shows this research is basically intended to explore the academic and environmental stress usually experienced among the College of Education students. In doing so, as the stressors form academic and environmental corners are numerous, this research will focus merely on the above mentioned areas. For this reason stressors like teachers, exam, course load, study skills, results, and peer pressure are from the academic stress side. Stressors like Transportation, weather, crowd, dormitory service, cafeteria, entertainment, and administration are also from the environmental stress. Finally, the results obtained from assessing the academic and environmental and academic stress was looked to find the

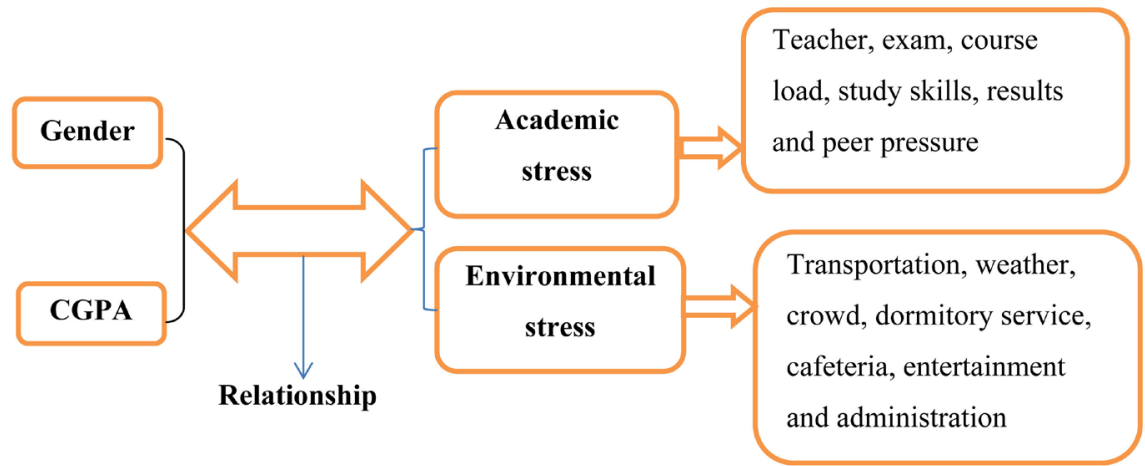

Figure 1. The conceptual framework of the study. 
type and strength of its relationship with the two variables (i.e., Gender and Cumulative GPA).

\section{Literature Review}

\section{The concept of Stress}

Stress is a normal and inevitable part of life. Mild level of stress is good; it can encourage and support us to become more productive. However, too much stress, or a strong response to stress can be harmful. The social, physical and psychological consequences of stress are determined by how we perceive a stress provoking event and how we react to it. We may be motivated and invigorated by certain events in our lives and consider them as "stressful". Thus, we may respond in a negative manner that could inflict negative effects on our physical, mental, and social well-being [4].

Stress is simply the body's non-specific response to any demand made on it. Stress is not by definition synonymous with nervous tension or anxiety. Stress provides the means to express talents and energies and pursue happiness; it can also cause exhaustion and illness, either physical or psychological; heart attacks and accidents. The important thing to remember about stress is that certain forms are normal and essential. As the body responds to various forms of physical or psychological stress, certain predictable changes occur. These include increased heart rate, blood pressure (systolic and diastolic), and secretions of stimulatory hormones. These responses to stress will occur whether the stress is positive or negative in nature. In lay terms, it is known as the "fight or flight" mechanism. Continual exposure lowers the body's ability to cope with additional forms of psychological or physiological stress [5].

Stress is viewed as a negative emotional, cognitive, behavioural and physiological process that occurs as a person tries to adjust to or deal with stressors [6]. [7] regard stress as an unpleasant state of emotional and physiological arousal that individuals experience in situations that they perceive as dangerous or threatening to their well-being. The circumstance that disrupts, or threatens to disrupt, individuals' daily functioning and cause people to make adjustments are stressors.

However, stress is perceived in different ways and may mean different thing to different individuals. It is perceived as events or situations that cause individuals to feel tension, pressure, or negative emotions including anxiety and anger. Moreover, other people define stress as the response to existing situations, which includes physiological changes (increased heart rate, and muscle tension), emotional and behavioural changes [6]. Stress is always regarded as a psychological process that involves an individual's personal interpretation and response to any threatening event [1].

It is important to note that stress can have both positive and negative effects on people. It means that stress may be a normal, adaptive reaction to threat. Its role is to signal and prepare individuals to take defensive action. Take for in- 
stance, fear of things that present realistic threats motivates individuals to deal with them or avoid them. Most psychologists assert that moderate stress motives individuals to achieve and fuels creativity, although stress may hinder individuals from performance on difficult tasks [7].

[7] argue that stress can leads to serious problems if it is not managed effectively. Moreover, when a person is exposed to chronic stress, she or he is likely to experience both physical illness (including heart disease), and mental illness (e.g., anxiety disorders). The field of Health Psychology focuses in part, on how stress affects bodily functioning and on how people can use stress management techniques to prevent or minimize disease.

\section{Stressors}

Stress can come from any situation or thought that makes you feel frustrated, angry, or anxious. Everyone sees situations differently and has different coping skills. For this reason, no two people will respond exactly the same way to a given situation [4].

[8] defined stressor as anything that challenges any individual's adaptability or stimulates an individual's body or mentality. Stress can be caused by environmental factors, psychological factors, biological factors, and social factors. It can be negative or positive to an individual, depending on the strength and persistence of the stress, the individual's personality, cognitive appraisal of the stress and social support.

Similarly, [9] defined stressors as factors or stimulators that cause psychological and physical stress. Some scientists classify these stressors according to their frequency or duration.

This research particularly emphasizes on academic and environmental stressors that impedes the college life of students.

\section{Academic stress}

Academic stress is a kind of stress caused due to increase in the class workload, inferior status than predicted, expectation of graduation, and severe disagreement with the mentors. All adolescent students experience academic stress in their academic life [10]. [11] also defined academic stress as a students' cognitive reaction to the demands related to academics that exceed the available resources o (internal or external). Academic stress booms individual's perception of academic frustration, academic conflict, academic pressure and academic anxiety which are the components of academic stress. Likewise, [12] defined academic stress as a mental and emotional pressure or tension that occurs due to the painful demands of college life. The constituents of academic stress are originated from being exposed to new educational concepts, adjusting to new social settings, and taking on the larger workload. Too much academic stress can contribute to depression and physical illness, which can in turn negatively affect students' academic performance.

Academic stress in college level arises from overcrowded lecture halls, semester system, and inadequate resources to perform academic work [13]. The pressure to perform well in the examination or test and time allocated makes aca- 
demic environment very stressful [14].

Findings from a study by [15] reported that academic stressors originate from family expectation, teachers' expectations, competition with other students and excessive course work or workload. The study shows that, of all the academic stressors, family expectations (52.7\%) and teacher expectations (32.4\%) contributed the most (i.e. $52.7 \%$ and $32.4 \%$ respectively) in inflicting high stress level among the participants. Therefore, this finding shows that family expectations and teacher expectations are factors which were largely responsible for causing academic stress among the respondents.

Academic stress impedes the smooth going of college students in achieving their optimal academic performance. It takes a lot more than just studying to achieve a successful college career. Different stressors such as time management and social activities can all pose their own threat to a student's academic performance. A student's GPA determines many things such as class rank and entrance to graduate school. Much research has been done looking at the correlation of many stress factors that college students' experience and the effects of stress on their GPA [16].

Research has found that stress levels among female college students is elevated compared to males [17]. Possible explanations for female students experiencing higher stress levels could include women taking on the role of being the caretaker of the family while also working and being a successful student [18]. According to [18] "Women usually report a higher level of self-imposed stress and report more physiological reactions to stressors than males, while males report lower stress levels because they are taught to be masculine and not show emotional weakness". In some, college students face higher stress levels given the various activities and obligations required of them. Female college students are even more susceptible to higher stress levels than males. This can often impact student's health as well as their academic performance [19].

A study by [20] shows that the difference between male and female undergraduates was not statistically significant. The undergraduate students experienced highest stress levels due to the increased class workload, followed by the pressure and having many hours of studies, and the financial difficulties; and occasionally stressed the computer problems factors. The gender difference exists only with regard to a handful stressor. Female students appeared to experience higher degree of stress than their male peers due to the increased class work overload, having many hours of studies, pressure, and financial difficulties, fighting with a boyfriend/ girlfriend, lack of social support, lack of university support, missing some lectures, lack of vacations or breaks and health problems.

\section{Environmental stress}

Transition of students from school environment to university environment could cause a psychological, academic and social shock to them, since this educational system has huge differences. In this level, students face new methods of teaching, new academic requirements, new type of relations between students and faculties and even new relations among students themselves. In Jordan, 
most schools are unisex so students' co-education will have new types of relations with the opposite sex. Due to these changes, students can potentially experience different types of stress that can affect their mental health, social health and their academic achievement [21].

The environment pressurizes a person with forceful and challenging demands to adjust. The environmental stressors include weather, noise, crowding, pollution, traffic, unsafe and substandard housing, and crime [4].

[22] enumerated the following as constituents of environmental stress,

$\checkmark$ Peers treating freshers unlike the way treat each other

$\checkmark$ Faculty treating different peer groups differently

$\checkmark$ Need to mingle with peers of different race/ethnicity on campus

$\checkmark$ Finding support groups sensitive to specific needs

$\checkmark$ Living in the local community

$\checkmark$ Adjusting to the campus environment

$\checkmark$ Participating in class

$\checkmark$ Meeting with faculty

To explore the relationship between gender and environmental stress, a study conducted in Sweden by [20] disclosed that male students experience a relatively higher stress than their female students when placed in unfamiliar situations. Similarly, a study by [23] explained that girls are more vulnerable to stress that comes as a result of the academic aspects of life and work. Therefore, they are inflicted more with environmental stress in their college than boys did.

\section{Stress management strategies in college students}

The response we made to our external environment determines our physical and psychological health. Thus, developing awareness on ourselves and our response to stress-provoking situations enhances our skill in handling stress. In its more acceptable meaning, stress management is not about learning how to avoid or escape the stressful situations in life, rather it is about learning to develop an appreciate skill of reacting to these pressurizing situations and enhancing one's own adjustment. Through learning stress management, we clearly understand the mind-body connection, thereby we build our physical and psychological health [4].

College students are exposed to a considerable amount of stress, which necessitate successful and constantly changing coping strategy [2]. A study conducted by [24] in China reveals that the commonly practiced stress coping strategies among college students are,

1) Adapt to college life as soon as possible and improve the effect of study

2) Improve college students' ability of starting a career and establish a correct concept of career

3) Guide college students to rational consumption and help students with financial difficulties

4) Cultivate the interpersonal skills of college students

5) Ease the mental stresses caused by family conditions in time

Similarly, a study by [25] showed that some of the common coping techniques 
practiced by college students are proper utilization of time, involving in leisure related activities, optimistic appraisal and support from friends and family often relieves stress in students. Furthermore [26] expressed that different coping methods such as finding help, solving problem, leisure, exercise, cognitive-restructuring, and a sense of security were found to be beneficial.

\section{Methods}

The research team approached the study through descriptive research design. Particularly, a survey method was used to collect the data from the targeted population. To obtain the data, a self-developed academic and environmental stress scale (questionnaire) was utilized. The questionnaire includes 44-items in five point scale with values ranging from 1 (strongly disagree) to 5 (strongly agree). The academic and environmental stress scale was intended to investigate the level academic and environmental stress arising from academic and environmental stressors. The Cronbach's Alfa statistical analysis indicated that the reliability of academic and environmental stress scale found to be 0.78 and 0.58 , respectively.

The questionnaires were distributed among a total of 77 students of $2^{\text {nd }}, 3^{\text {rd }}$, and $4^{\text {th }}$ year degree and diploma program who were drawn from all the departments in the CoE. Both random and convenient sampling strategies were applied to select the participants from the target population. In this $51.9 \%$ are males and $48.1 \%$ were females. According to their CGPA, 33.8\% of them are in the range $1.75-2.39,32.5 \%$ are in $2.40-2.79$, and $33.8 \%$ falls in $2.80-4.00$. $46.8 \%$ of the participant students are from second year, $31.2 \%$ are from third year, and $22.1 \%$ are from the fourth year. Age wise, majority of the students (72.7) are from 18 to 22 . From the rest 9.1 are in the age $23-27$ and $18.2 \%$ are in the age 28 and above.

The questionnaire had a separate section to investigate the stress copping practiced by college students. Moreover, the questionnaire was having four open ended items provided to explore the stress coping strategies and students' awareness on the usage of the guidance and counselling service in the college.

The questionnaire has three sections:

1) Section I-Personal information: expected to gather data like age, gender, year of study, CGPA, department, program (degree/diploma), student parent's address and the like.

2) Section II-This section includes both academic and environmental stress scales. These scales encompass a total of 43 items.

3) Section III-Four open ended items which directly assist the activity of Guidance and Counselling centre in the CoE. These items were prepared to investigate the current stress coping strategies which are used by the college students.

Besides to the questionnaire, intensive focus group discussions were conducted among a total of 30 students from the CoE. These discussions were completed in three sessions that extended for about two hours each. 
To analyse the quantitative data, different descriptive and inferential statistical techniques were utilized for each stressor. The SPSS (Statistical Packages for Social Sciences) software was applied to carry out the data computation. Moreover, the additional qualitative data were analysed through thematic data processing, i.e., inductive data analysis. Similarly, the focus group interview results were qualitatively analysed by identifying similarities of the participant opinions.

\section{Results}

The Focus group discussion as well as the open-ended items of the questionnaire intensively explored the academic and environmental stressors. The stress management strategies usually practiced by the college students were also identified. The stressors that commonly known to inflict stress among the College of Education students is summarized as follows.

\section{1) Academic stressors}

As indicated in Figure 2, under the academic stress teachers, course load, results, exam, peer and time are explore and found to have the above mentioned contribution in inflicting academic stress among the college students.

\section{2) Environmental stressors}

As denoted in Figure 3, all the mentioned environmental stressors are found to have their own failures and bother students in their daily activities.

\section{Stress copping strategies}

As the focus group interview participants addressed, they commonly go out for walk with friends, working with classmates, listen to music and watch movies, taking alcohol or cigarette, going for asleep, and share ones feelings or problems to a trusted one. Moreover, the findings from the questionnaire reveals that majority of the college students practice various positive copping strategies like playing sport, chatting with roommates, going for tea with friends, listening to music, watching movies, reading books (like Bible or Quran, fictions and newspapers) and going for walk. Some of them shared as they visit their families, sleep, cry, taking a bath, deep breath, watch football games (like Premier League), visit church or mosque and use internet service when they get stressed. A very few of them also reveals that they practice visiting the GCC to tackle their feeling of stress.

With regard to the usage of the services delivered in the $G C C$, most of the participants informed as they have never visited center when they get stressed. Of all the participants, three students visited the center to get a professional support. A very few of them also shared as they have visited the center for a different purpose. They informed as they have visited to get help in their academics, especially in doing their assignments. The very few students visited the center underscored as the service provided is helpful and inviting with important advice. However, they shared as the office setting is not improved.

The questionnaires distributed among the selected participants came up with the following results, 


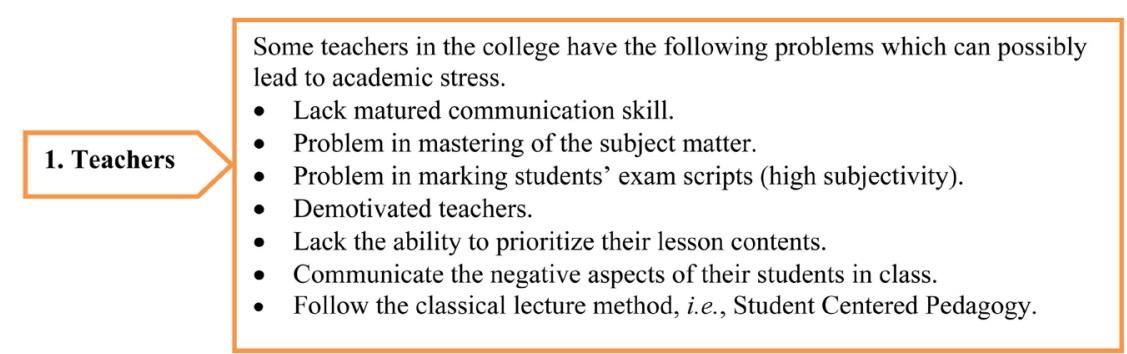

\begin{tabular}{|l|l|}
\hline - Some include unnecessary/irrelevant stuffs in their course contents. \\
- Repetition of contents in different courses \\
Pressuring assignments and projects with no guide for students on how to \\
prepare it. Some consider giving assignments to relieve themselves from \\
their own duty. \\
- Do not read mood and accessibility of students to electronic devices of \\
their students \\
- Course contents are all form European context, difficulties in \\
contextualizing it to the life experiences of their students. \\
- Lack of learning facilities that fits to the level of the students. \\
- Some teachers end courses without covering all contents. \\
- Some content of courses are out-dated. They simply serve for a long \\
period of time without modification.
\end{tabular}
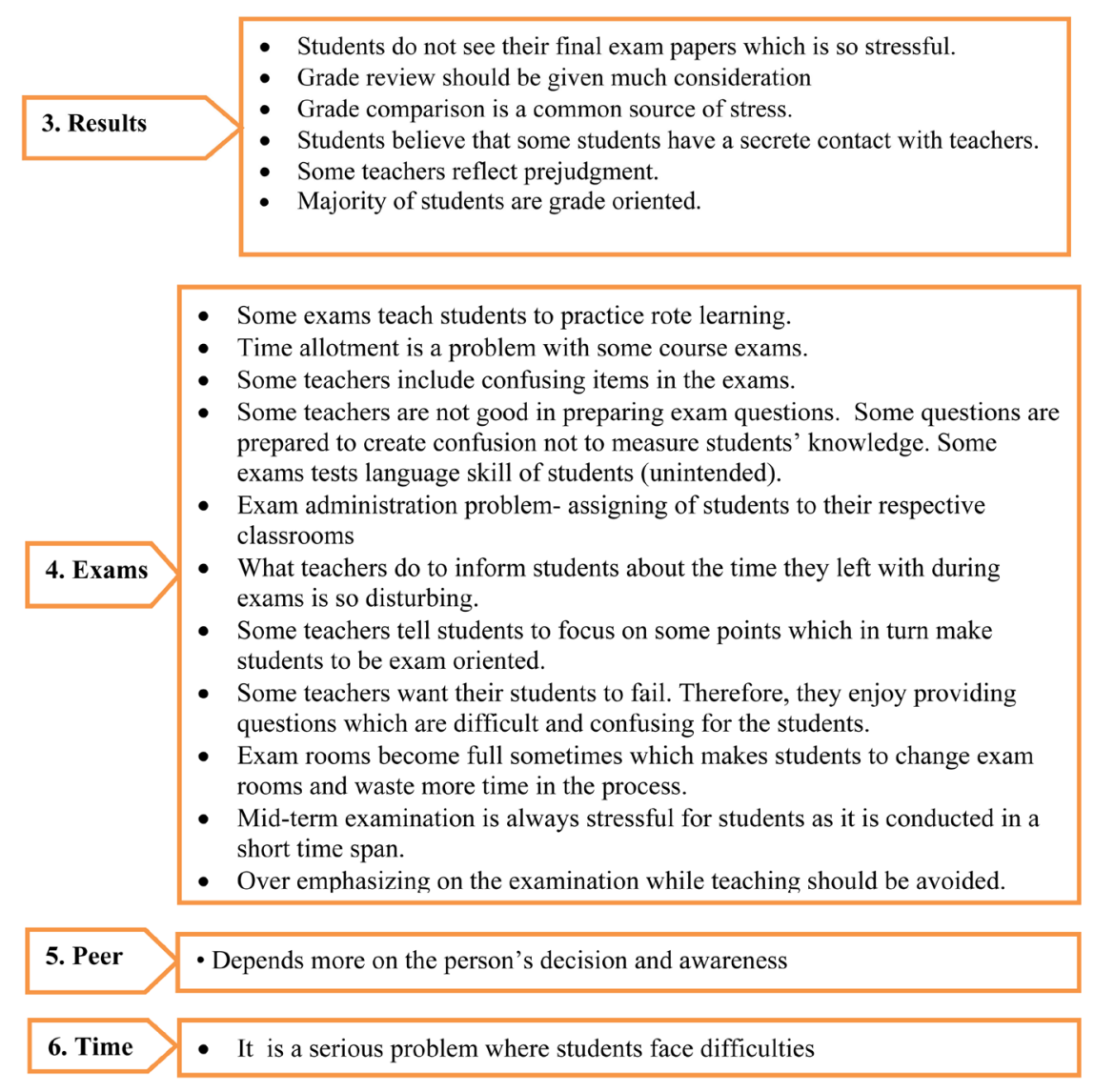

Figure 2. Academic stressors.

\section{Academic Stress}

Table 1 shows that there are no students with a low academic stress. $83.1 \%$ of the students are having a moderate level of academic stress and the rest $16.9 \%$ 


\begin{tabular}{|l|l|}
\hline Infrastructure & $\begin{array}{l}\text { Poor classroom infrastructure } \\
\text { Toilet for girls has no hygiene }\end{array}$ \\
\hline Library & Out dated books and limited time for service delivery \\
\hline Administratio & So bureaucratic starting from the registrar office. \\
\hline Internet service & Poor connection and outdoor (not comfortable with cold) \\
\hline Dormitory & Cold with humidity, exposed to disturbances \\
\hline Stationery & Stationary available with unfair price. \\
\hline
\end{tabular}

Figure 3. Environmental stressors.

Table 1. Level of academic stress.

\begin{tabular}{ccccc}
\hline & Frequency & Percent & Valid Percent & Cumulative Percent \\
\hline Moderate Academic Stress & 64 & 83.1 & 83.1 & 83.1 \\
High Academic Stress & 13 & 16.9 & 16.9 & 100.0 \\
Total & 77 & 100.0 & 100.0 & \\
\hline
\end{tabular}

have a high level of academic stress.

\section{Academic stress level and gender}

As indicated in Table 2, the mean score of academic stress is $78.5 \%$ and 82.9 among males and females, respectively.

As presented in Table 3, there is no males or females experience low level of stress. Majority of the males (90\%) and females (76\%) have a moderate level of academic stress. The rest very few of them bother with a high level of academic stress.

The chi-square test result in Table 4 indicates that the chi-square value is $2.859, \mathrm{df}=2$, and $p=0.094$. Therefore, as the $\mathrm{p}$ value is greater than the decided probability value $(0.05)$, there is no statistically significant difference between male and female students on their level of academic stress.

\section{Academic stress level and Cumulative GPA}

The chi-square test result in Table 5 and Table 6 indicates that the chi-square value is $3.079, \mathrm{df}=2$, and $p=0.196$. Therefore, as the $\mathrm{p}$ value is greater than the decided probability value (0.05), there is no statistically significant difference between cumulative GPA and the level of academic stress.

\section{Environmental stress}

Table 7 shows that there are very few number of students (9.1\%) experiencing a low academic stress. $63.6 \%$ of the students are having a moderate level of academic stress and the rest $27.3 \%$ have a high level of academic stress. 
Table 2. Academic stress level and gender.

\begin{tabular}{ccccc}
\hline Gender & N & Mean & Std. Deviation & Std. Error Mean \\
\hline Male & 40 & 78.4500 & 10.17778 & 1.60925 \\
Female & 37 & 82.9189 & 14.25049 & 2.34277 \\
\hline
\end{tabular}

Table 3. Academic stress level and gender.

\begin{tabular}{lcccc}
\hline & \multicolumn{3}{c}{ Academic Stress Level } & \multirow{2}{*}{ Total } \\
\cline { 3 - 4 } & & Moderate Academic Stress & High Academic Stress & \\
\hline \multirow{3}{*}{ Gender } & Male & 36 & 4 & 40 \\
& Female & 28 & 9 & 37 \\
& Total & 64 & 13 & 77 \\
\hline
\end{tabular}

Table 4. Chi-square test for gender and level of academic stress.

\begin{tabular}{|c|c|c|c|c|c|}
\hline & Value & df & $\begin{array}{c}\text { Asymp. Sig. } \\
\text { (2-sided) }\end{array}$ & $\begin{array}{l}\text { Exact Sig. } \\
\text { (2-sided) }\end{array}$ & $\begin{array}{l}\text { Exact Sig. } \\
\text { (1-sided) }\end{array}$ \\
\hline Pearson Chi-Square & $2.810^{\mathrm{a}}$ & 1 & 0.094 & & \\
\hline Continuity Correction $^{\mathrm{b}}$ & 1.882 & 1 & 0.170 & & \\
\hline Likelihood Ratio & 2.859 & 1 & 0.091 & & \\
\hline Fisher's Exact Test & & & & 0.130 & 0.085 \\
\hline Linear-by-Linear Association & 2.774 & 1 & 0.096 & & \\
\hline $\mathrm{N}$ of Valid Cases & 77 & & & & \\
\hline
\end{tabular}

Table 5. Academic stress and cumulative GPA.

\begin{tabular}{lccccc}
\hline & & \multicolumn{3}{c}{ Cumulative GPA } & Total \\
\cline { 3 - 5 } & & $\mathbf{1 . 7 5}-\mathbf{2 . 3 9}$ & $\mathbf{2 . 4 0}-\mathbf{2 . 7 9}$ & $\mathbf{2 . 8 0}-\mathbf{4 . 0 0}$ & \\
\hline \multirow{2}{*}{ Academic Stress Level } & Moderate Ac Stress & 23 & 18 & 23 & 64 \\
& High Ac Stress & 3 & 7 & 3 & 13 \\
& Total & 26 & 25 & 26 & 77 \\
\hline
\end{tabular}

Table 6. Chi-square test for academic stress and cumulative GPA.

\begin{tabular}{cccc}
\hline & Value & df & Asymp. Sig. (2-sided) \\
\hline Pearson Chi-Square & $3.260^{\mathrm{a}}$ & 2 & 0.196 \\
Likelihood Ratio & 3.079 & 2 & 0.214 \\
Linear-by-Linear Association & 0.000 & 1 & 1.000 \\
N of Valid Cases & 77 & & \\
\hline
\end{tabular}

Table 7. Level of academic stress.

\begin{tabular}{cccc}
\hline & Frequency & Percent & Valid Percent \\
\hline Low Environmental Stress & 7 & 9.1 & 9.1 \\
Moderate Environmental Stress & 49 & 63.6 & 63.6 \\
High Environmental Stress & 21 & 27.3 & 27.3 \\
Total & 77 & 100.0 & 100.0 \\
\hline
\end{tabular}




\section{Environmental stress and gender}

As presented in Table 8, there is a very few number of males (5\%) or females (14\%) experience a low level of environmental stress. Majority of the males $(60 \%)$ and females $(68 \%)$ have a moderate level of academic stress. The rest very few of them (35\% males and 19\% females) bother with a high level of academic stress.

The chi-square test result in Table 9 indicates that the chi-square value is $3.610, \mathrm{df}=2$, and $p=0.17$. Therefore, as the $\mathrm{p}$ value is greater than the decided probability value (0.05), there is no statistically significant difference between cumulative GPA and the level of academic stress.

\section{Environmental stress and CGPA}

According to Table 10 results, no student from the second categories of the cumulative GPA (2.40 - 2.79) has a low level of academic stress. However, 19\% from the first category $(1.75-2.39)$ and $8 \%$ from the third category $(2.80-4.00)$ experience a moderate level of stress. The rest very few which are $12 \%, 32 \%$, and $38 \%$ of the three categories of the cumulative GPA, respectively have a high level of environmental stress.

The chi-square test result in Table 11 indicates that the chi-square value is $11.707, \mathrm{df}=4$, and $p=0.047$. Therefore, as the $\mathrm{p}$ value is less than the decided probability value (0.05), there is slight statistically significant difference between cumulative GPA and the level of environmental stress.

Table 8. Environmental stress and gender.

\begin{tabular}{cccccc}
\hline & \multicolumn{4}{c}{ Environmental Stress Level } & \\
\cline { 3 - 6 } & & Low & $\begin{array}{c}\text { Moderate } \\
\text { Environmental Stress }\end{array}$ & $\begin{array}{c}\text { High } \\
\text { Environmental Stress }\end{array}$ & Environmental Stress \\
\hline \multirow{2}{*}{ Gender } & Male & 2 & 24 & 14 & 40 \\
& Female & 5 & 25 & 7 & 37 \\
\multicolumn{2}{c}{ Total } & 7 & 49 & 21 & 77 \\
\hline
\end{tabular}

Table 9. Chi-square test for environmental stress and gender.

\begin{tabular}{cccc}
\hline & Value & df & Asymp. Sig. (2-sided) \\
\hline Pearson Chi-Square & $3.528^{\mathrm{a}}$ & 2 & 0.171 \\
Likelihood Ratio & 3.610 & 2 & 0.164 \\
Linear-by-Linear Association & 3.471 & 1 & 0.062 \\
N of Valid Cases & 77 & & \\
\hline
\end{tabular}

Table 10. Environmental stress and cumulative GPA.

\begin{tabular}{ccccc}
\hline & \multicolumn{3}{c}{ Environmental Stress Level } & \\
\cline { 2 - 5 } & $\begin{array}{c}\text { Low } \\
\text { Environmental Stress }\end{array}$ & $\begin{array}{c}\text { Moderate } \\
\text { Environmental Stress }\end{array}$ & $\begin{array}{c}\text { High } \\
\text { Environmental Stress }\end{array}$ \\
\hline $1.75-2.39$ & 5 & 18 & 3 & 26 \\
$2.40-2.79$ & 0 & 17 & 8 & 25 \\
$2.80-4.00$ & 2 & 14 & 10 & 26 \\
Total & 7 & 49 & 21 & 77 \\
\hline
\end{tabular}


Table 11. Chi-square test for environmental stress and cumulative GPA.

\begin{tabular}{cccc}
\hline & Value & Df & Asymp. Sig. (2-sided) \\
\hline Pearson Chi-Square & $9.622^{\mathrm{a}}$ & 4 & 0.047 \\
Likelihood Ratio & 11.707 & 4 & 0.020 \\
Linear-by-Linear Association & 5.742 & 1 & 0.017 \\
N of Valid Cases & 77 & & \\
\hline
\end{tabular}

The each items analyses indicates that spending time to search for information, comparing current and high school results, less interesting courses, inability to attain good marks as expected in the college, and joining to a wrong department or college inflict a higher level of stress among the college students. Similarly, items related to lack of electricity supply, poor latrine service, inadequacy of study rooms, waiting in a long queue to obtain services, and lack of access to transportation service are among the factors that cause a higher level of environmental stress.

\section{Discussion}

Stress occurs in every part of our life. Recent research reports show that the prevalence of stress is increasing among students. This is due to various factors such as increased pressure, competition, decreased resources, inadequate family support, exposed to violence through media and increased use of alcohol as well as drugs [27].

In concord to this idea, this study reveals that majority of the College of Education students experience a moderate level of academic stress. No students were found to experience a low level of academic stress. The main sources of academic stress among these students is known to arise from teachers, academic results, exams, peer pressures, time management and course load. Similarly, a study by [2] shows that the main academic stressors are family expectation, teachers' expectations, competition with other students and excessive course work or workload. Of all the academic stressors, family expectations $(52.7 \%)$ and teacher expectations (32.4\%) contributed the most (i.e. $52.7 \%$ and $32.4 \%$ respectively) towards the stress level of the participants.

Findings of this study show that there is no significant relationship found between gender and the level of academic stress. In contrary to this, a study conducted in University of Arkansas at Little Rock found that female accounting students reported higher stress scores than their male counterparts. Furthermore, the results indicated that this phenomenon affected their academic performance negatively [28]. Furthermore, this study reveals that there is no significant relationship between CGPA of the college students and the level of academic stress. Unlike to this result, responses from the Dental Environment Stress (DES) questionnaire indicated that there is a strong relationship between stress and academic performance [28]. 
The findings of this study also reveal that majority of the students in the College of Education experience a moderate level of environmental stress with a very few of them feel a low level of environmental stress. In contrast to this, a study by [10] reported that students in the college do not worry much about environmental stressor because the administration office plays a great role in resolving it. Moreover, this study shows that there is no significant relationship found between gender and the level of environmental stress. In contrary to this finding, [9] found that female students had more stress than males; this could be explained by the fact that females are more subjected to the community pressure and are under the pressure of the cultural habits. A similar study report shows that lack of vacations/breaks scored higher mean for female students $(M=3.27)$, compared to the male students $(M=3.00)$ due to being placed in an unfamiliar situations [20].

However, merely the level of environmental stress was found to have a statistically slight significant relationship with the CGPA of the college students. With regard to this, [21] shared that environmental stress related to new methods of teaching, new academic requirements, new type of relations between students and faculties and even new relations among students themselves could possibly lessens the academic performance of college students.

The each items analyses indicates that spending time to search for information, comparing current and high school results, taking less interesting courses, inability to attain good marks as expected in the college, and joining to a wrong department or college inflict a higher level of stress among the college students. A similar study report shows that time allowed, aptitude, quality of instruction and ability to understand instructions were among the most stressful academic aspects [16]. With regard environmental stressors, items related to lack of electricity supply, poor latrine service, inadequacy of study rooms, waiting in a long queue to obtain services, and lack of access to transportation service are among the factors that cause a higher level of environmental stress. Likewise, [10] explained that Computer associated problems, positioned in a new place, staying in the academic place for extended period of time, transformation in the living environment causes the environmental stress among the students in the college level.

This study reports that majority of the students in the college practice healthy stress coping strategies like engaging in sports, reading, watching movies, listening to music, waking, chatting with friends, etc. A similar study conducted in Tafila Technical University, Jordan indicated that $70.5 \%$ of the students use various positive approaches in managing their stress like playing basketball or swimming [9]. Likewise, a study by [2] shows that the most common and effective positive coping strategies that both male and female college students use are meditation and prayer followed by listening to music or watching television, sleep, pursuing hobby or interest, talking to parents or any family members and exercise or yoga respectively. 


\section{Conclusions}

Stress is an inevitable life confrontation commonly apparent among college students. It usually arises from various academic, social, environmental, physical and psychological aspects. To combat stress students always practice various positive and negative mechanisms. However, when stress exceeds the controlling capability of the student it urgently needs some personal management techniques or professional assistance. In this present study, majority of the students in the college are found to experience a moderate to high level of academic and environmental stress as a result of various stressors. The stressors explored to inflict stress among the students arise from teachers, exams, course loads, peer pressure, academic results and time management. However, to tackle their stressful situation most of the students are also found to prefer more positive copping strategies than the negative ones. They are found to mitigate their stress feeling through various healthy practices like engaging in sports, reading, watching movies, chatting with friends, etc. Furthermore, the study reveals that variables like gender and CGPA are having no statistically significant relationship with the levels of academic and environmental stress excluding the slight statistically significant relationship found between CGPA and the level of environmental stress.

To sum up, this research was done with certain limitations that should not be left unmentioned. These were like limited sample number and lack of time and enough financial support to extend the study as it is needed to be.

\section{Acknowledgements}

This research work is financially and technically supported by Finnish Church Aid (FCA).

\section{Conflicts of Interest}

The authors declare no conflicts of interest regarding the publication of this paper.

\section{References}

[1] Hamaideh, S. (2011) Stressors and Reaction to Stressors among University Students. International Journal of Social Psychiatry, 57, 69-80. https://doi.org/10.1177/0020764009348442

[2] Pariat, L., Rynjah, A. and Kharjana, M.G. (2014) Stress Levels of College Students: Interrelationship between Stressors and Coping Strategies. Journal of Humanities and Social Science (IOSR-JHSS), 19, 40-46.

[3] Scott, M.S.E. (2009) Stress in College: Common Causes of Stress in College. Academic Publishing, Lambert.

[4] Klinic Community Health Centre (2010) Stress and Stress Management. Klinic Community Health Centre, Winnipeg.

[5] National Health Ministries (2006) Stress and the College Student. PC, USA.

[6] Bernstein, D.A., Penner, L.A., Stewart, A.C. and Roy, E.J. (2008) Psychology. 8th 
Edition, Houghton Mifflin Company, Boston.

[7] Auerbach, S.M. and Gramling, S.E. (1998) Stress Management: Psychological Foundations. Prentice Hall, Upper Saddle River.

[8] Devi, R.S. and Mohan, S. (2015) A Study on Stress and Its Effects on College Students. International Journal of Scientific Engineering and Applied Science (IJSEAS), 1, 449-456.

[9] Thawabieh, A.M. and Qaisy, L.M. (2012) Assessing Stress among University Students. American International Journal of Contemporary Research, 2, 110-116.

[10] Baskar, D. (2015) A Conceptual Analysis on Stress among College Students. Paripex-Indian Journal of Research, 4, 225-226.

[11] Krishnan, L. and Sequeira, A.H. (2007) Stress among College Students and How to Combat It. http://ssrn.com/abstract=2041423

[12] De Deyn, R. (2008) A Comparison of Academic Stress among Australian and International Students. UW-L Journal of Undergraduate Research XI, 1-4.

[13] Awino, J.O. and Agolla, J.E. (2008) A Quest for Sustainable Quality Assurance Measurement for Universities: Case of Study of the University of Botswana. Educational Research Review, 3, 213-218.

[14] Erkutlu, H.V. and Chafra, J. (2006) Relationship between Leadership Power Bases and Job Stress of Subordinates: Example from Boutique Hotels, Manage. Res. News, 29, 285-297. https://doi.org/10.1108/01409170610674419

[15] Kharjana, G.M., Pariat, L., Rynjah, A. and Joplin (2014) Stress Levels of College Students: Interrelationship between Stressors and Coping Strategies. IOSR Journal of Humanities and Social Science (IOSR-JHSS), 19, 40-46.

[16] Nandamuri, P.P. and Ch, G. (2007) Sources of Academic Stress-A Study on Management Students. Journal of Higher Education, 61, 31-42.

[17] Melinda, S., Ellen, J.G., Jeannne, S. and Robert, S. (2008) Preventing Burnout: Signs, Symptoms, Causes and Coping Strategies.

http://www.helpguide.org/mental/burnout_signs_symptoms.htm

[18] Stevenson, A. and Harper, S. (2006) Workplace Stress and the Student Learning Experience. Quality Assurance Education, 14, 167-178. https://doi.org/10.1108/09684880610662042

[19] Magill, R., Flack, C., Garcia, A. and Edwards, M. (2017) Stress Levels of College Students by Gender. Research Project. California State University, Monterey Bay.

[20] Yumba, W. (2008) Academic Stress: A Case of the Undergraduate Students. Institutionen för beteendevetenskap och lärande, Linköping.

[21] Hussien, T. and Hussien, S. (2006) Strategies for Coping Educational and Psychological Stress. Dar Alfiker, Amman.

[22] Rajasekar, D. (2013) Impact of Academic Stress among the Management Students. AMET International Journal of Management, 32-40.

[23] Kumar, S. and Bhukar, J.P. (2013) Stress Level and Coping Strategies of College Students. Journal of Physical Education and Sports Management, 4, 5-11.

[24] Chang, K. and Lu, L. (2007) Characteristics of Organizational Culture, Stressors and Wellbeing: The Case of Taiwanese Organizations. Journal of Management and Psychology, 22, 549-568. https://doi.org/10.1108/02683940710778431

[25] Blake, R.L. and Vandiver, T.A. (1988) The Association of Health with Stressful Life Changes, Social Supports, and Coping. Family Practice Research Journal, 7, 205-218.

[26] Donaldson, D., Prinstein, M.J., Danovsky, M. and Spirito, A. (2000) A Pattern of 
Children's Coping with Life Stress: Implications for Clinicians. American Journal of Orthopsychiatry, 70, 351-359. https://doi.org/10.1037/h0087689

[27] Kadhiravan, S. and Kumar, K. (2012) Enhancing Stress Coping Skills among College Students. Journal of Arts, Science and Commerce, 4, 49-55.

[28] Gabre, H.G. and Kumar, G. (2012) The Effects of Perceived Stress and Facebook on Accounting Students' Academic Performance. Accounting and Finance Research, 1, 87-100. https://doi.org/10.5430/afr.v1n2p87 